\title{
KEMARAHAN PADA PEREMPUAN KANKER GINEKOLOGI
}

\author{
Alia Isna Yudianti ${ }^{1}$, Efri Widianti $^{2}$, Sheizi Prista Sari ${ }^{3}$ \\ 1,2,3 Fakultas Keperawatan Universitas Padjadjaran \\ email: alisyudianti@gmail.com
}

\begin{abstract}
The background of this research is the high rate of gynecology cancer prevalence which influences the psychological effect called maladaptive anger response in women diagnosed with gynecology cancer. The purpose of this research is to identify the representation of anger in women diagnosed with gynecology cancer at one of the hospital in Kota Bandung. This research used a descriptive design which variable is anger in women diagnosed with gynecology cancer. This research involved 50 respondents were taken based on accidental sampling as long as three weeks. The instrument was using STAXI-2 which had already adopted in Indonesia and the validity is 0,85 and the reliability value is 0,89 . The data analyzed using mean and serves in a frequencies distribution form. The result showed that almost all of the respondents (92\%) has low state anger, almost all the respondents (94\%) has low trait anger, most of respondents (78\%) has moderate control out and moderate (84\%) control in, and all the respondents (100\%) has low index angry expression. Most of the respondents has low intensity of anger, state anger, and also they can't express their anger adaptively. Respondents prefer push their anger to themselves but in time, anger will appear in a strong enough intensity. Suggested a nurse can develope and give some consultation and therapy to patients diagnosed with gynecology cancer, so they can express their anger in an adaptive way.
\end{abstract}

Keywords : Handover, Patient safety, Nurse

\section{ABSTRAK}

Penelitian ini dilatarbelakangi oleh tingginya angka kejadian kanker ginekologi yang direspon secara psikologis berupa kemarahan maladaptif oleh perempuan yang mengidap kanker ginekologi. Tujuan dari penelitian ini adalah untuk mengetahui gambaran kemarahan pada perempuan kanker ginekologi di salah satu rumah sakit di Kota Bandung. Penelitian dilakukan dengan desain deskriptif kuantitatif, variabelnya adalah kemarahan perempuan kanker ginekologi. Responden yang dilibatkan berjumlah 50 orang diambil berdasarkan accidental sampling yang diambil dalam tiga minggu. Instrumen yang digunakan dalam penelitian ini adalah STAXI-2 yang telah diadaptasi ke dalam bahasa Indonesia dengan validitas sebesar 0,85 dan reliabilitas sebesar 0,89 . Data dianalisis menggunakan nilai mean dan disajikan dalam bentuk distribusi frekuensi. Hasil dari penelitian menunjukkan hampir seluruh responden (92\%) memiliki intensitas kemarahan (state anger) yang rendah, hampir seluruhnya (94\%) memiliki sifat kemarahan (trait anger) rendah, sebagian besar responden $(78 \%)$ memiliki nilai control out sedang dan control in sedang $(84 \%)$, dan seluruh (100\%) responden memiliki nilai indeks ekspresi kemarahan rendah. Sebagian besar responden memiliki intensitas dan sifat kemarahan rendah dan kurang mampu mengekspresikan kemarahannya. Responden cenderung menekan rasa marah tetapi sewaktu-waktu akan muncul dalam intensitas yang cukup kuat. Disarankan untuk perawat agar dapat memberikan 
konsultasi dan terapi bagi pasien kanker ginekologi agar mereka dapat mengekpresikan kemarahannya secara adaptif..

Kata kunci : Kanker ginekologi, kemarahan, perempuan.

\section{PENDAHULUAN}

Kanker merupakan suatu istilah bagi penyakit. Kanker adalah kondisi sel yang telah mengalami kehilangan pengendalian dan mekanisme normalnya sehingga pertumbuhannya tidak normal, cepat, dan tidak terkendali (Rasjidi, 2010). Pertumbuhan sel-sel kanker yang abnormal akan menyebabkan jaringan tumbuh menjadi besar dan membuat sebuah benjolan yang dikenal dengan nama tumor yang bersifat ganas dan bisa juga bersifat kronis.

Kanker pada saat ini merupakan salah satu penyakit yang menyebabkan angka kejadian kematian pada manusia meningkat. Terdapat 7,9 juta orang atau sekitar $13 \%$ kematian di seluruh dunia yang disebabkan oleh kanker (WHO, 2008 dalam depkes RI, 2014). Menurut American Cancer Society (ACS), pada tahun 2011, sekitar 1.437.180 kasus kanker baru didiagnosis dan hampir setengahnya berakhir dengan kematian. Data statistik lainnya menyebutkan setiap tahunnya sebanyak 8,2 juta orang di dunia meninggal akibat kanker (International Agency for Research on Cancer, 2012 dalam WHO, 2013).

Peningkatan kejadian kanker berdampak negatif pada sektor ekonomi dan produktivitas. Hal tersebut sangat mempengaruhi kondisi fisik dan psikologis penderita. Dampak fisik yang ditimbulkan dapat berupa gangguan pada organ tubuh, baik dampak dari penyakit kankernya maupun dampak dari pengobatannya. Rasa nyeri dan disfungsi fisik akan dirasakan (Greenwald, McCorkle, 2007 dalam Landrine, Russo, 2011). Efek dari pengobatan kanker sendiri dapat mengakibatkan kerusakan tubuh bahkan berpotensi menyebabkan hilangnya fungsi tubuh yang tidak dapat diperbaiki. Seringkali juga pasien merasa kecewa karena harus kehilangan salah satu organ tubuhnya. Dampak psikologis yang dirasakan antara lain seperti kecemasan, kemarahan, ketidakberdayaan, rasa malu, harga diri, dan stres (Oetami, 2012). Menurut penelitian yang dilakukan oleh Duck-Hee Kang, Na-Jin Park, dan Traci McArdle pada tahun 2012, perempuan yang terdiagnosis mengidap kanker ginekologi akan mengalami stres dan gangguan mood berupa kemarahan. Menurut Bhave dan Saini (2009) manusia harus mempelajari bagaimana mengekspresikan emosi yang dirasakan tanpa menyakiti orang lain dan mampu beradaptasi terhadap hal yang membuat marah.

Respon psikologis yang dialami seseorang karena kehilangan terbagi menjadi lima tahap menurut teori KublerRoss (1969). Respon ini dinamakan "The Five Stages of Grief". Menurut teori Kubler-Ross respon psikologis ini terbagi menjadi penyangkalan (denial), marah (anger), tawar menawar (bargaining), depresi (depression), dan penerimaan (acceptance). Lima tahap respon psikologis ini dapat digunakan untuk mengidentifikasi individu pasca pengahadapan masalah dalam hidupnya seperti bencana, kehilangan anggota tubuh, kecelakaan, masalah sosialekonomi, penyakit berat, dan lain-lain. Teori ini dapat digunakan untuk memahami reaksi individu pasca kejadian 
traumatik yang dialami olehnya. Apabila individu tersebut dapat melalui tahaptahap tersebut dan mencapai tahap penerimaan, maka individu tersebut akan mampu mengakhiri proses berduka dan mengatasi masalah kehilangan secara tuntas.

Pada tahap penyangkalan (denial) Reaksi pertama yang akan ditunjukkan adalah terkejut, tidak percaya, merasa terpukul, dan menyangkal pernyataan bahwa kehilangan itu benar-benar terjadi (Suliswati, 2005). Terkadang individu pada tahap ini mengalami halusinasi. Individu yang sedang dalam tahap ini akan menolak semua fakta, informasi, dan tentang segala sesuatu yang berhubungan dengan kejadian yang dialaminya karena tidak percaya dengan hasil diagnosis. Pada tahap ini, individu akan kehilangan cara berpikir untuk mencari solusi dan jalan keluar dari masalah yang dialaminya. Individu cenderung bingung dengan apa yang terjadi pada dirinya dan tidak siap untuk menerima keadaan yang menimpanya.

Di tahap selanjutnya yaitu marah, respon yang ditunjukkan oleh individu dapat diungkapkan dengan berbagi cara. Individu mungkin akan menyalahkan diri sendiri, orang lain, serta pada lingkungan sekitar individu. Individu merasa kecewa karena proses kehidupan tidak sejalan dengan keinginannya. Dalam tahap ini individu tidak membutuhkan nasihat, karena nasihat tersebut akan membuat individu lebih terganggu. Menurut individu tersebut nasihat adalah sebuah judgement atau pengadilan terhadap dirinya. Bila tahapan ini berlangsung selama 6 bulan pasca berduka, maka individu tersebut masih berada dalam respon normal, namun bila lebih dari 6 bulan pasca berduka, maka individu tersebut berespon secara maladaptif dan dapat menimbulkan masalah baru.
Tahap tawar menawar (bargaining) merupakan tahap selanjutnya yang dilalui oleh individu pasca kehilangan. Bila sudah masuk pada tahap ini individu akan berpikir seandainya dia dapat menghindari hal yang terjadi pada dirinya. Reaksi yang sering terlihat adalah dengan mengungkapkan perasaan bersalah atau rasa ketakutan atas dosa yang telah diperbuat baik itu secara nyata atau hanya imajinasinya saja (Kozier, 2010). Seringkali individu yang berada pada tahap ini cenderung melakukan tawar menawar dengan Tuhan agar kejadian yang dialaminya tidak benarbenar terjadi dan agar tidak menimpanya. Namun sebenarnya individu tersebut sudah dapat melihat realita yang ada dalam hidupnya.

Pada tahap depresi (depression) Individu sering menunjukkan sikap menarik diri dari lingkungan sekitarnya, tidak mau berbicara, takut, perasaan tidak menentu, dan putus asa. Reaksi fisik yang sering diperlihatkan antara lain seperti menolak makan, susah tidur, letih, dan libido menurun (Suliswati, 2005). Pada tahap ini, individu juga berisiko tinggi untuk melakukan bunuh diri. Bila individu sedang berada dalam tahap ini, lebih baik individu tersebut tidak ditinggalkan dan harus selalu ditemani.

Tahap selanjutnya adalah tahap penerimaan (acceptance). Tahap ini berkaitan dengan penyusunan ulang perasaan kehilangan. Individu akan menyadari bahwa hidup individu tersebut harus terus dijalani dan harus mencari makna baru dari keadaan individu tersebut sekarang. Individu pada tahap ini mulai menyusun rencana yang akan dilakukan pasca menghadapi kehilangan (Kozier, 2010).

Tidak semua individu yang mengalami kehilangan berespon secara adaptif. Semua tahapan tersebut pasti 
dilalui namun dengan waktu yang berbeda pada setiap individu. Apabila individu tersebut dapat melalui tahap-tahap tersebut dan mencapai tahap penerimaan, maka individu tersebut akan mampu mengakhiri proses berduka dan mengatasi masalah kehilangan secara tuntas. Penghadapan individu terhadap masalah yang dialaminya bergantung pada strategi koping dan penerimaan individu tersebut (Kozier, 2010).

Salah satu tahap respon berduka yang dilalui oleh individu adalah kemarahan. Tahap kemarahan seringkali terabaikan, padahal dapat menimbulkan masalah yang cukup berbahaya pada individu. Contohnya bila individu tersebut menderita suatu penyakit maka individu tersebut cenderung akan menolak pengobatan, berperilaku agresif, dan menarik diri dari lingkungan (Choi, et al., 2015). Tentu saja hal tersebut dapat mengganggu proses pengobatan pada pasiena.

Marah merupakan suatu kondisi emosi yang berisi perasaan-perasaan dengan berbagai intensitas, mulai dari perasaan jengkel yang ringan sampai rasa marah yang kuat (Spielberger et al., 1999). Kemarahan seseorang adalah hal yang paling mecolok terlihat dan dapat menimbulkan konflik batin berkepanjangan. Kemarahan dapat memicu tindakan kekerasan, baik kekerasan yang dilakukan pada diri sendiri maupun kekerasan yang dilakukan ke orang lain. Hal ini dapat memunculkan konflik sosial. Kemarahan bisa menghancurkan sebuah hubungan, obstruksi jalan pikir dalam menyelesaikan masalah, dan meningkatkan risiko penarikan diri dari masyarakat (Gautam, 2008). Ini akan menjadi masalah baru dalam hidup individu tersebut.

Respon terhadap marah dapat diungkapkan melalui tiga cara, yaitu: mengungkapkan secara verbal, menekan, dan menantang. Dari ketiga cara respon marah ini, cara pertama adalah konstruktif sedangkan dua cara lainnya bersifat destruktif. Kemarahan diawali oleh adanya stresor yang berasal dari dalam maupun luar. Stresor dari dalam berupa penyakit, hormonal, dendam, dan kesal. Sedangkan stresor yang berasal dari luar dapat berasal dari ejekan, cacian, makian, hilangnya benda berharga, bencana, dan lain-lain. Hal tersebut akan menyebabkan kehilangan atau gangguan pada sistem individu (Disruption and Loss) (Yosep \& Sutini, 2014).

Bila rasa marah tersebut diterima dengan respon maladaptif, maka akan menyebabkan komplikasi lain. Menurut Margaret dan M.Mitchell (2004) bila respon kemarahan menjadi maladaptif, perempuan tersebut cenderung akan melakukan tindakan kekerasan, menyendiri, mengalami depresi brekepanjangan, bahkan hingga berisiko tinggi bunuh diri.

Kemarahan yang diekspresikan dengan respon maladaptif, disebut dengan agresifitas, akan menyebabkan suatu dampak. Berkowitz (1995) dalam Stephanie et al. (2012) menyatakan bahwa agresi adalah segala bentuk perilaku yang dimaksudkan untuk menyakiti seseorang, baik secara fisik maupun psikis.

Menurut Buss dan Perry (1992) dalam Stephanie et al. (2012) menyatakan bahwa agresi terbagi menjadi : agresi fisik (physical aggression), agresi verbal (verbal aggression), kemarahan (anger), dan permusuhan (hostility). Bila respon marah maladaptif, akan meningkatkan tanda depresi dan kecemasan (Allan \& Gilbert, 2002 dalam Stephanie et al., 2012). 


\section{METODE PENELITIAN}

Penelitian ini dirancang dengan menggunakan desain deskriptif kuantitatif. Penelitian ini dilakukan pada 50 orang responden dengan teknik accidental sampling dalam waktu tiga minggu di Ruang Y RS. X Kota Bandung. Variabel dalam penelitian ini merupakan variabel tunggal yaitu kemarahan pada perempuan.

Instrumen yang digunakan dalam penelitian ini berupa kuesioner dengan nama State Trait Anger Expression Inventory-2 (STAXI-2). Instrumen ini dikembangkan oleh Spielberger dan Reheiser pada tahun 1999 dan telah diterjemahkan dalam bahasa Indonesia serta telah diujicobakan di Indonesia

Berdasarkan skor STAXI-2, kemarahan dapat dikategorikan menjadi rendah $(<30)$, sedang (31-44), dan tinggi $(>45)$. Kemarahan dikatakan adaptif jika rentang skor individu berada dalam rentang sedang. Bila rentang nilai individu rendah, maka responden cenderung mengalami kemarahan maladaptif yang diekspresikan dengan cara yang seakanakan kontruktif tapi sebenarnya destruktif. Begitu juga bila rentang nilai kemarahan individu tinggi, maka individu tersebut cenderung mengekspresikan kemarahannya dengan agresi dan tindakan kekerasan.

\section{HASIL PENELITIAN}

Penelitian ini dilakukuan di salah satu rumah sakit di Kota Bandung dan telah mendapatkan ijin dari rumah sakit tersebut.

\section{Keadaan Kemarahan (Anger Experience) \\ Gambaran pengalaman kemarahan responden dapat dilihat pada Tabel 1}

Tabel 1: Distribusi frekuensi Keadaan Kemarahan (State Anger) responden $(\mathrm{n}=50)$

\begin{tabular}{|c|c|c|}
\hline Kategori & Frek & $\%$ \\
\hline State Anger & & \\
\hline rendah & 46 & 92 \\
\hline sedang & 4 & 8 \\
\hline tinggi & 0 & 0 \\
\hline Feeling angry & & \\
\hline rendah & 39 & 78 \\
\hline sedang & 9 & 18 \\
\hline tinggi & 2 & 4 \\
\hline Angry verbally & & \\
\hline rendah & 44 & 88 \\
\hline sedang & 4 & 8 \\
\hline tinggi & 2 & 4 \\
\hline Angger Physically & & \\
\hline rendah & 50 & 100 \\
\hline sedang & 0 & 0 \\
\hline tinggi & 0 & 0 \\
\hline
\end{tabular}

Tabel 1 menunjukan bahwa rentang nilai tertinggi state anger, feeling angry, anger verbally, dan anger physically termasuk dalam kategori rendah. Hal ini berarti perempuan kanker ginekologi tidak mengalami kemarahan yang tinggi, baik merasa marah, marah yang diungkapkan secara verbal, dan marah yang diungkapkan secara fisik. Semuanya dalam rentang rendah.

Sementara itu, Tabel 2 menunjukan bahwa rentang nilai trait anger, angry temperament, dan angry reaction tertinggi berada dalam rentang rendah. Baik sifat kemarahan ataupun reaksi kemarahan nilainya berada dalam rentang rendah semua. Hal ini dapat diartikan bahwa perempuan kanker ginekologi memiliki sifat kemarahan yang rendah. Meskipun demikian, meskipun sedikit, terdapat juga beberapa responden yang sifat kemarahannya berada dalam rentang sedang dan tinggi. 
Tabel 2. Distribusi Frekuensi Sifat Kemarahan (Trait Anger) pada Perempuan Kanker Ginekologi di RS. X Kota Bandung ( $n=50)$

\begin{tabular}{|c|l|l|}
\hline \multicolumn{1}{|c|}{ Kategori } & Frek & $\%$ \\
\hline Trait anger & & \\
\hline rendah & 47 & 64 \\
\hline sedang & 3 & 6 \\
\hline Angry Temperament & & \\
\hline rendah & 44 & 100 \\
\hline Angry Reaction & & \\
\hline rendah & 44 & 80 \\
\hline sedang & 4 & 18 \\
\hline tinggi & 2 & 2 \\
\hline
\end{tabular}

Sedangkan nilai anger expression index, anger out.control out, dan control in dapat dilihat pada Tabel 3

Tabel 3. Distribusi Frekuensi Sifat Kemarahan (Trait Anger) pada Perempuan Kanker Ginekologi di RS. X Kota Bandung $(n=50)$

\begin{tabular}{|c|l|l|}
\hline Kategori & Frek & $\%$ \\
\hline Anger expresion index & & \\
\hline rendah & 50 & 100 \\
\hline Anger out & & \\
\hline rendah & 48 & 96 \\
\hline sedang & 2 & 4 \\
\hline Angry in & & \\
\hline rendah & 45 & 90 \\
\hline sedang & 5 & 10 \\
\hline Control out & & \\
\hline Rendah & 1 & 2 \\
\hline Sedang & 39 & 78 \\
\hline Tinggi & 10 & 20 \\
\hline Control in & & \\
\hline Rendah & 1 & 2 \\
\hline Sefang & 42 & 84 \\
\hline Tinggi & 7 & 14 \\
\hline
\end{tabular}

Tabel 3 menunjukan hasil nilai anger expression index, anger out, dan anger in tertinggi berada dalam rentang rendah. Sedangkan nilai control out dan control in tertinggi berada pada rentang sedang, namun nilai control in lebih banyak dalam rentang sedang. Artinya, perempuan kanker ginekologi cenderung mengontrol kemarahannya yang ditekan ke dalam dirinya. Responden juga cenderung kurang mampu mengekspresikan kemarahannya karena nilai anger expression index seluruh responden berada dalam rentang rendah.

\section{PEMBAHASAN}

Pengalaman kemarahan terdiri dari keadaan kemarahan (state anger) dan sifat kemarahan (trait anger). Pada hasil penelitian ditemukan nilai state anger responden berada dalam rentang rendah, artinya responden merasakan marah dalam intensitas yang cukup jarang. Nilai trait anger responden berada dalam rentang rendah pula yang berarti responden memiliki sifat kemarahan rendah. Sebagian kecil dari responden memiliki rentang nilai state anger dan trait anger yang sedang. Berarti, sebagian kecil responden tersebut cukup merasa marah dan responden tersebut memiliki sifat marah yang sedang.

Sifat kemarahan perempuan yang terdignosis kanker ginekologi cenderung memiliki rentang rendah dalam menerima keadaan yang tidak menyenangkan dalam dirinya. Hal ini dapat dilihat dari sub skala trait anger yaitu angry temperament dan angry reaction.

Nilai angry temperament dan angry reaction sama-sama berada dalam rentang rendah. Angry temperament adalah kemarahan yang muncul tanpa adanya stimulus apapun. Sedangkan angry reaction adalah kemarahan yang muncul karena adanya stimulus negatif. Meskipun kedua sub skala tersebut berada dalam rentang rendah, namun nilai dari angry reaction lebih besar daripada nilai angry temperament, yang berarti kermarahan responden cenderung muncul setelah ada stimulus negatif.

Nilai state anger yang berada dalam rentang sedang lebih banyak dibandingkan dengan nilai trait anger yang 
dalam rentang sedang. Ini berarti perempuan yang terdiagnosis kanker ginekologi jarang merasakan kemarahan namun bila perempuan tersebut merasakan kemarahan, rasa marah akan muncul dengan intensitas yang cukup kuat. Hal ini juga berarti perempuan yang terdiagnosis kanker ginekologi cenderung mengalami perasaan marah akibat mengalami kejadian yang tidak menyenangkan pada dirinya. Bila individu memiliki nilai trait anger yang lebih tinggi dan nilainya dalam rentang yang tinggi juga, individu tersebut memiliki rasa marah yang tinggi dan cepat frustasi bila mengalami hal yang tidak menyenangkan dalam dirinya (Spielberger, 1999).

Sama halnya dengan rentang nilai ekspresi kemarahan (anger expression). Didapatkan hasil nilai ekspresi kemarahan responden dalam rentang yang rendah pula. Artinya responden kurang mampu mengekspresikan kemarahannya. Rentang nilai sedang anger in pun ditemukan lebih banyak dibandingkan rentang nilai anger out. Begitu juga dengan rentang nilai control in dan rentang nilai control out. Kedua sub variabel ini rentang nilainya berada dalam rentang sedang namun lebih banyak control in yang berada dalam rentang sedang. Artinya responden cenderung berusaha menekan perasaan marah mereka dan memilih untuk memendamnya dan tidak diungkapkan, responden juga cenderung mengontrol rasa marahnya ke dalam dirinya (dengan cara mendinginkan pikiran) daripada mengeluarkan rasa marah yang dirasakan oleh dirinya.

Dalam hal ekspresi kemarahan seseorang pasti akan diikuti oleh pengontrolan diri terhadap rasa marah tersebut. Kontrol kemarahan dikelompokkan juga menjadi dua sub skala juga yaitu control in dan control out.
Lebih banyaknya nilai anger in dan control in pada responden menunjukkan bahwa ekspresi berbanding terbalik satu sama lain. Semakin tinggi kontrol yang dilakukan maka semakin rendah ekspresi yang akan dilakukan dan sebaliknya, semakin rendah kontrol dilakukan maka semakin tinggi ekspresi kemarahan yang dilakukan (Dewi, 2004). Hasil penelitian juga menunjukkan nilai indeks ekspresi kemarahan berada dalam rentang rendah. Indeks ekspresi marah menunjukkan gambaran interaksi antara mekanisme pengontrolan rasa marah dan ekspresi kemarahan yang muncul pertama kali yang dilakukan oleh responden. Indeks ekspresi kemarahan bergantung pada nilai kontrol kemarahan, baik control in maupun control out. Bila nilai kontrol tinggi maka nilai indeks ekspresi kemarahan akan tinggi pula.

Bila nilai indeks ekspresi kemarahan dibandingkan dengan nilai seringnya kemarahan muncul (trait anger) terlihat skala trait anger memiliki nilai yang lebih rendah daripada indeks ekspresi kemarahan, namun bila dilihat dari sub skala trait anger terlihat nilai anger in lebih besar daripada nilai anger out. Ini berarti perempuan yang terdiagnosis kanker ginekologi cenderung menekan rasa marahnya kedalam diri sendiri.

Dalam interpretasi STAXI-2 dijelaskan pula bahwa individu dengan skor anger in yang lebih tinggi dibandingkan dengan skor anger out cenderung memiliki tingkat kecemasan yang tinggi dan berlebihan. Selain itu, individu tersebut cenderung akan melakukan tindakan kekerasan, baik pada dirinya sendiri atau pada orang lain (Spielberger \& Reheiser, 1999).

Hasil penelitian pada variabel ekspresi kemarahan ini sesuai dengan penelitian Gautam (2008) bahwa rasa marah merupakan respon sekunder dari 
perasaan sedih, kesepian, dan ketakutan serta lebih ditekan. Perempuan juga cenderung mengutamakan perasaan dibandingkan dengan logika dan perempuan cenderung tidak memperlihatkan rasa marahnya (Kang, et al., 2012).

Rasa marah yang ditekan dan tidak dikeluarkan cenderung akan menimbulkan distres emosional dan menambah masalah pada individu tersebut. Mengekspresikan rasa marah dengan cara menekan rasa marah juga akan meningkatkan risiko depresi, frustasi, dan keputusasaan (Moscoso, 2010). Hal lain juga diungkapkan oleh Cox, et al. (2004) bahwa perempuan yang mengekspresikan rasa marahnya dengan cara menekan perasaan marahnya cenderung rentan terhadap depresi dan kecemasan yang berlebihan. Kemarahan juga merupakan hal yang berkaitan erat dengan gangguan kecemasan (Deschenes, et al., 2011).

Rasa marah yang ditekan dan tidak diungkapkan merupakan rasa marah yang disampaikan secara konstruktif padahal sebenarnya rasa marah tersebut merupakan hal yang destruktif. Rasa marah yang ditekan ini cenderung memicu akumulasi perasaan dan gangguang mood berkepanjangan yang pada akhirnya akan merusak kondisi psikis maupun fisik individu. Tentu saja ini akan menjadi masalah baru bagi individu. Ketidakmampuan individu untuk mengekspresikan rasa marahnya akan memicu akumulasi rasa dendam (Hamid, 2008).

Oleh karena keadaan tersebut, pencegahan komplikasi akibat kemarahan tersebut sangat penting dilakukan. Peran perawat juga menjadi sangat penting dalam mengkaji keadaan psikologis pasien serta latar belakang psikologis pasien, terutama tentang kemarahan pada pasien.

\section{KESIMPULAN}

Hampir seluruh responden (92\%) memiliki nilai keadaan kemarahan (state anger) dalam rentang rendah, artinya responden, yaitu perempuan kanker ginekologi di Ruang $Y$ di RS. X Kota Bandung tidak dalam keadaan marah. Begitu juga dengan nilai sifat kemarahan, hampir seluruh responden (94\%) memiliki nilai sifat kemarahan (trait anger) dalam rentang rendah, artinya perempuan kanker ginekologi di Ruang $Y$ RS. X Kota Bandung mengalami intensitas marah yang jarang.

Seluruh responden (100\%) memiliki nilai ekspresi kemarahan (anger expression) yang berada dalam rentang rendah, artinya responden, yaitu perempuan kanker ginekologi di Ruang $Y$ RS. X Kota Bandung kurang mampu mengekspresikan kemarahannya. Meskipun pada hasil penelitian nilai kemarahan keseluruhan perempuan yang mengidap kanker ginekologi rendah, bila rasa marah tersebut muncul maka kemarahan akan muncul dalam intensitas yang cukup kuat karena responden cenderung menekan rasa marahnya dan kurang mampu mengekspresikan keamarahan yang dirasakannya

\section{SARAN}

Untuk pelayanan kesehatan, terutama RS. $X$ Kota Bandung perlu memberikan konseling pada perempuan yang mengidap kanker ginekologi, tidak hanya mengonsultasikan masalahnya tetapi juga mengkaji latar belakang masalah psikologis pasien. Konseling dapat dilakukan oleh tenaga kesehatan yang memiliki spesialisasi dalam ilmu jiwa, khususnya perawat jiwa sehingga kemarahan pada perempuan yang mengidap kanker ginekologi yang destruktif dan maladaptif dapat diantisipasi. 
Selain itu, perlu ada penelitian lebih lanjut terkait dengan kemarahan pada perempuan kanker ginekologi, terutama yang melihat faktor-faktor apa saja yang memengaruhi kemarahan pada perempuan kanker ginekologi, serta desain penelitian juga dapat dilakukan dengan desain kualitatif agar menggambarkan lebih jelas tentang kemarahan pada perempuan kanker ginekologi.

\section{DAFTAR PUSTAKA}

American Cancer Society. 2011. http://www.cancer.org: Breast Cancer Facts and Figures 2011-2012 (diakses pada 28 Desember 2015).

Barinkova, Karolina., Margarita, M. 2013. Anger, Coping, and Quality of Life in Female Cancer Patients. Slovakia: Department of Psychology, University of Pavol Jozef Safarik.

Bhave, Swati Y., Saini, Sunil. 2009. Anger Management. New Delhi : SAGE Publications India. (diunduh pada 29 Desember 2015).

Choi, Eunji., Yoon, Y. L., Hyo, J. Y., Sangeun, L., Mina, S., Boyoung, P., Jae, K. J., Yeol, K., Kui, S. C. 2015. Relationship between Cancer Worry and Stages of Adoption for Breast Cancer Screening among Korean Women. Center Korea.

Cox, D. L., Velsor, P. V., \& Hulgus, J. F. 2004. Who me, angry? Patterns of Anger Diversion in Women. Health Care for Women International.
Deschenes, Sonya D., Micahel J. D., Katie F., \& Naomi Koerner. The Role of Anger in Generalized Anxiety Disorder. 2011. Canada : Concordia University.

Dewi, Z. L. 2004. Antesedan, Pengalaman, Ekspresi, dan Kontrol Marah pada Orang Batak dan Orang Jawa. Universitas Indonesia. Ganong, William S. 2004. Review of Medical Physiology. San Francisco: Elsevier.

Gautam, Anju. 2008. Anger and Its Management. India : Indian Association of Health Research and Walfare.

Hamid, A. Y. 2008. Bunga Rampai Asuhan Keperawatan Kesehatan Jiwa. Jakarta: EGC

Kang, Duck-Hee., Na-Jin P., Traci, McArdle. 2012. Cancer-Specific Stress and Mood Disturbance: Implications for Symptom Perception, Quality of Life, and Immune Response in Women Shortly after Diagnosis of Breast Cancer. USA: University of Texas School of Nursing.

Kubler-Ross, Elizabeth. 1969. On Death and Dying. New York: Macmillan.

Landrine, Hope., dan Nancy F. Russo. 2010. Handbook of Diversity in Feminist Psychology. New York : Springer Publishing Company. (diunduh pada 29 Desember 2015).

Lyons, Margaret A., M.Mitchell. 2004. Psychosocial Impact of Cancer in 
Low-Income Rural/Urban Women : Phase II. Capstone College of Nursing, University of Alabama.

Meiser, Bettina., Margaret, G., Kaaren, W., Michelle, P., Elvira, Z., Kristine, B. S., Christobel, S., Gillian, M., Judy, K. 2012. Getting to the Point: What Women Newly Diagnosed With Breast Cancer Want to Know About TreatmentFocused Genetic Testing. Oncology Nursing Forum.

Moscoso, Manolete S. 2010. Construct Validity of the Emotional Distress Inventory in Patients with Cancer. University of South Florida USA.

Oetami, Fratiwi., M. Thaha, I. L., \& Wahiduddin. 2014. Analisis Dampak Psikologis Pengobatan Kanker Payudara di RS Dr. Wahidin Sudirohusodo Kota Makassar. Universitas Hasanuddin.
Potter, Patricia A., Perry, Anne G. 2006. Fundamentals of Nursing: Concepts, Process, and Practise. USA: Mosby

Spielberger, C. D., Eric, C. R., Marsh, B. J., Owen, A. E., \& Sydeman, S. J. 1999. Measuring Anxiety and Anger with State-Trait Anxiety Inventory (STAl) and the State-Trait Anger Expression Inventory 2 STAXI 2. Palo Alto, $\mathrm{CA}$ : Consulting Psychologist Press.

Suliswati. 2005. Konsep Dasar Keperawatan Jiwa. Jakarta: EGC..

World Health Organization. 2013. http://www.WHO.go.org : Insidens Kanker Ginekologi. diakses pada 28 Desember 2015.

Yosep, lyus., Titin Sutini. 2014. Buku Ajar Keperawatan Jiwa dan Advance Mental Health Nursing. Bandung: PT Refika Aditama 